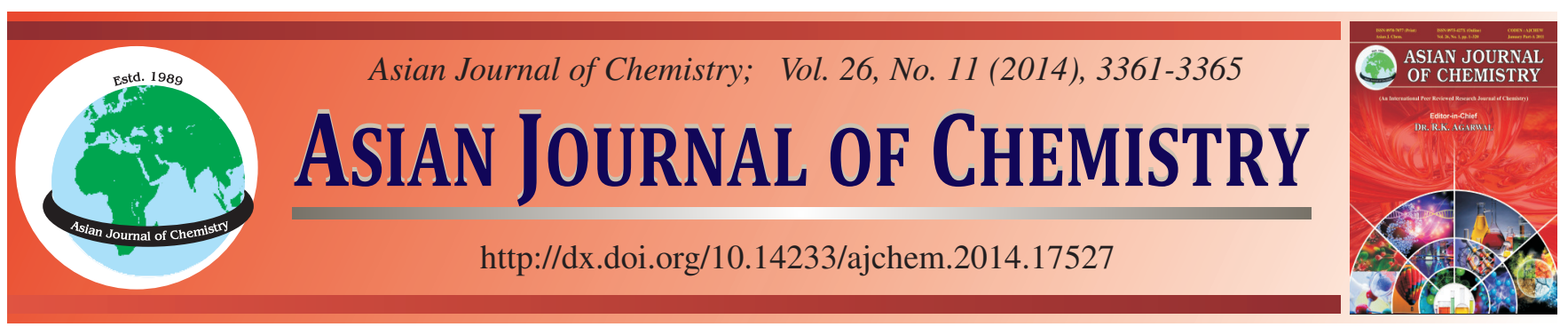

\title{
Social Sustainable Development of Population Agglomeration and Pollution Emission in Urban China: A Case Study of Beijing and Shanghai
}

\author{
Huinui HaO
}

School of Resources and Economic Trade, Zhengzhou Institute of Aeronautical Industry Management, Henan, P.R. China

Corresponding author: Tel: +86 13526665996; E-mail: haoletter@126.com

Received: 14 February 2014;

Accepted: 16 April 2014;

Published online: 25 May 2014;

AJC-15249

\begin{abstract}
Because of the superior condition in the China's big cities, a lot of labors were attracted to enter, which caused a lot of hidden trouble for the city. This paper builds the coupling coordination model to explore the interactional relationship between the population agglomeration, the environment and social economic factors based the data of Beijing and Shanghai from 2000 to 2012. With the empirical research on the present situation of coordinated development of population agglomeration, environment and social economy system, this paper discusses the key factors of sustainable development. The results show that the coordination degree of two cities is weak and tend to verge disorders. The key factors that affect the coordination degree of the two cities are different. This paper provides some policy suggestions for the sustainable development of each city.
\end{abstract}

Keywords: Population agglomeration, Coupling coordination, Environment.

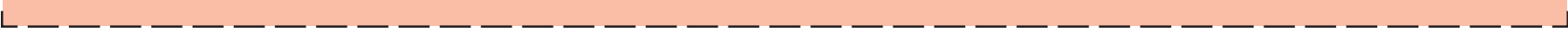

\section{INTRODUCTION}

With the economic development and the urbanization construction, large amount of surplus labours from rural areas swarm into urban areas to seek new development patterns. The great amount of floating labour force gathering in urban areas, especially gathering in and settling down in large cities, which results in the continuously enlargement of city size, traffic jam and overwhelming burden on public service systems such as education, medical treatment, etc. Meanwhile, many problems have occurred in urban life, including high housing price, difficulties in enrolling schools and receiving medical service, etc. All these problems have reduced the comfort level of urban life, while the trend of population swarming into urban areas is still going on.

At the same time, the industrial agglomeration and the population gathering bring about unduplicated pollution and damage on the air and environment etc. of urban areas. The current situation of eco-environment has been increasingly concerned. In addition, the frequent hazy weather in various regions recently has drawn extensive attention on the living condition and space and the pollution of economic development mode of high energy consumption on the environment and ecology etc. Meanwhile the government takes all kinds of measures and policies to treat the air and the eco-environment pollutions.
The high-speed growth of economy, the eco-environment deterioration and the resource depletion have influenced people's living quality. These factors influence the achievement of the sustainable development as well. Whether population gathering, economy and eco-environmental system can develop harmoniously or not and how to make them develop harmoniously are problems of important practical significance which affect the achievement of sustainable development.

Analysis of population agglomeration status of large cities in China: Since the reform and opening-up, cities in China have entered in a rapid development stage. Especially in recent years, due to the rapid development of urbanization, industries of large scale gathering in urban areas call for a great demand of labor force. Most of all, more social resources gather in large provincial capital cities such as Beijing, Shanghai, Guangzhou, Shenzhen etc., where develop a basin effect attracting labor force. In China, the proportion of urban population in the national population increased from $18.9 \%$ in 1978 to $52.6 \%$ in 2012 .

Population density: There was a sharp change in the data of population density in China in 2006. The population density increased from less than 1000 people $/ \mathrm{km}^{2}$ to a scope of more than 2000 people $/ \mathrm{km}^{2}$. And it shows the trend of increasing year by year (Fig. 1). 


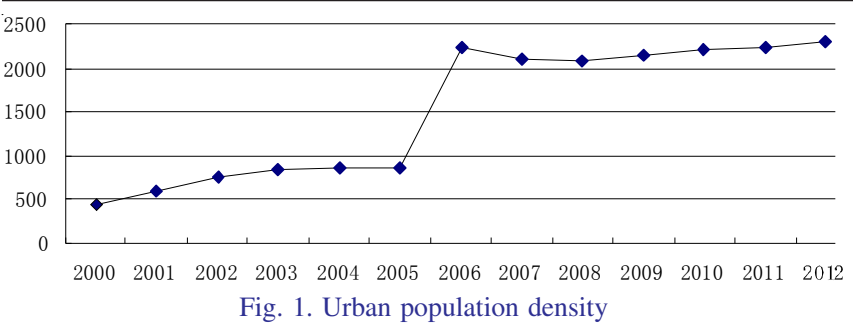

Especially in metropolises such as Beijing and Shanghai, due to the lessened limitation on population float, the incomparable environment attracts more population there. Owing to the restriction of household registration system, the permanent resident population without Beijing household takes up more than $40 \%$ of the whole population. In the core function areas of Beijing, the density of permanent resident population in 2012 was as high as 23758 people $/ \mathrm{km}^{2}$.

Population structure: The tremendous resources of good quality in large cities attract large population. For instance, more employment opportunities result in most of the population is young people of high quality. Take Beijing as an example, people from 20-45 accounts for more than 50\% of the permanent resident population. The sampled data of Beijing in 2012 showed that, more than one-third of the population above 6 possessed university degrees.

Higher population density and higher population quality has brought promote role to the city's economic construction and development, added the urban vitality, but also bring huge burden to the coordinated development of the city. The densely populated city, such as Beijing and Shanghai, has caused traffic congestion and increased the cost of living. Although in the economic structure of Beijing and Shanghai the third industry occupies larger, environmental resources have also been a great deal of damage, this urban development model can not be sustainable. This paper will build the coupling coordination development model to evaluation the sustainable development of the population, the social economic and environmental of Beijing and Shanghai.

Evaluation model of coupling coordinated development: In most literatures in recent years, the population, the economy and the eco-environment are not considered to develop at the same time; while they are considered to develop in the mode of mutual promotion and coupling cooperation. Many scholars in China employed coupling theory to investigate the coordinated development of the population, the economy and the eco-environment.

The concept of coupling was derived from physics. It refers to the phenomenon of two or more than two systems or motion forms influence each other through all kinds of interactions. When this concept is used in economics, the coupling relationship of the population agglomeration, social economic development and environment system is a dynamical correlation relationship of correlative dependence and mutual promotion, under the interaction of economic and environmental systems. The key of transition from unordered system to ordered one is the cooperative effect among the order parameters inside the system. It controls the characteristics and laws of the phase change of the system. Coupling degree is just the measurement of the cooperative effect.
Coupling degree: Based on the above knowledge, this research defined the degrees of the interactions of the respective coupling factors of the population agglomeration, social economic development and eco-environmental systems as the system coupling degrees. The value of this degree represents the coordination degree. The population agglomeration, economy and environment are non-linear systems and their evolution equations are shown as follows:

$$
\frac{\mathrm{dx}(\mathrm{t})}{\mathrm{dt}}=\mathrm{f}\left(\mathrm{x}_{1}, \mathrm{x}_{2}, \ldots, \mathrm{x}_{\mathrm{n}}\right), \mathrm{i}=1,2, \ldots, \mathrm{n}
$$

Build the function of population, social economic development and environmental systems:

$$
\begin{aligned}
& f(X)=\sum_{i=1}^{n} a_{i} x_{i}, i=1,2, \ldots, n \\
& f(Y)=\sum_{i=1}^{n} b_{i} y_{i}, i=1,2, \ldots, n \\
& f(Z)=\sum_{i=1}^{n} c_{i} z_{i}, i=1,2, \ldots, n
\end{aligned}
$$

where $\mathrm{x}_{\mathrm{i}}, \mathrm{y}_{\mathrm{i}}$ and $\mathrm{z}_{\mathrm{i}}$ represent the indexes in the population agglomeration, social economic and environmental system, respectively and $\mathrm{a}_{\mathrm{i}}, \mathrm{b}_{\mathrm{i}}$ and $\mathrm{c}_{\mathrm{i}}$ are the weights of the indexes, respectively.

The population agglomeration, economic and environmental system and their relationship were regarded as one system. The coupling degree models of the interactions of several systems were obtained by using the capacitive coupling concept and the coefficient models of this concept in physics.

$$
c=\left\{\frac{f(X) \times f(Y) \times f(Z)}{[f(X)+f(Y)+f(Z)]^{3}}\right\}^{1 / 3}
$$

where the value of coupling degree is in the range of $\mathrm{C} \in[0,1]$. This research measured the coupling degree of the three variables, namely the population, economic and environmental system and their relationship were regarded as one system. The coupling degree models of the interactions of several systems were obtained by using the capacitive coupling concept and the coefficient models of this concept in physics. Due to the two limit values of coupling degree were considered as well, the coupling degree $\mathrm{C}$ were classified into the following 6 categories: (1) when $\mathrm{C}=0$, the coupling degree of the population, economic and environmental systems is minimum. The three systems were independent to each other and developed disorderly; (2) when $\mathrm{C} \in[0,0.3]$, the population, economic and environmental systems were at a coupling stage of low level; (3) when $\mathrm{C} \in[0.3,0.5]$, the coupling of the population, economic and environmental systems turned into a primary stage; (4) when $\mathrm{C} \in(0.5,0.8]$, the coupling of the population, economic and environmental systems stepped into a runningin stage, where the three systems began to couple well; (5) when $\mathrm{C} \in(0.8,1]$, the coupling of the population, economic and environmental systems turned into an advanced stage; (6) 
and when $\mathrm{C}=1$, the coupling degree of the population, economic and environmental systems was maximum. The coupling of the three systems reached a benign resonance stage and was approaching to a new ordered structure.

Coordination degree: Coupling degree $\mathrm{C}$ just shows the direct interactions of the population, economic and environmental systems, while it fails in explaining the degree of the global function or coordinative development of the three systems. As a result, the coordination degree was introduced in this research. It is able to evaluate the coordination degree of the population, economic and environmental systems better. The coordination degree is calculated using the following formula:

$$
\left\{\begin{array}{c}
D=\sqrt{C \times T} \\
T=\alpha f(X)+\beta f(Y)+\delta f(Z)
\end{array}\right.
$$

where $\mathrm{D}$ is the development coefficient of coordination degree, $\mathrm{T}$ represents the comprehensive ranking index of the population economic development and environment, which states the overall coordinated efficiency and promotion of the population, economic development and eco-environment. Of which $\alpha$ and $\beta$ are undetermined coefficients. The three subsystems is interaction and mutual affect, in this paper the role of the three subsystems was same treated, took 1/3 (Table-1).

According to the value of coordination degree, this research established the ranking evaluation criterion of coordination degree of the population, economic and environmental systems. The value of is within the range of 0-1. According to different values, coordination degree is divided into the following degrees:

\section{Empirical analysis of the evaluation of systems coupling} coordinated development

Selection of index: On the basis of integrating the present research results, according to the requirements of actual development and following the scientific, system optimized, universal comparative and practicable principles, this research established the index system of the urban population, economy and environment coupling development. The index system is shown in Table-2.

Data source and standardized treatment: In this paper, sample data were obtained from the Beijing statistics yearbook and Shanghai statistical yearbook from 2001 to 2013, the Beijing environmental system index is derived from Beijing environment bulletin of each years. The data from the statistical yearbook have a certain accuracy and authority. For forward and reverse index, this paper uses the following formula (5) and (6) to make standardize processing, respectively.

$$
\begin{aligned}
& x_{i j}^{*}=\frac{x_{i j}-X_{\text {min }}}{X_{\text {max }}-X_{\text {min }}} \\
& X_{i j}^{*}=\frac{X_{\text {max }}-X_{i j}}{X_{\text {max }}-X_{\text {min }}}
\end{aligned}
$$

\begin{tabular}{|c|c|c|c|}
\hline \multicolumn{4}{|c|}{$\begin{array}{c}\text { TABLE-2 } \\
\text { INDEX SYSTEM }\end{array}$} \\
\hline \multirow{2}{*}{ Sub-system } & \multirow{2}{*}{ The index } & \multicolumn{2}{|c|}{ The weight of each index } \\
\hline & & Beijing & Shanghai \\
\hline \multirow{8}{*}{ Population system } & Permanent Population Density & 0.144 & 0.135 \\
\hline & Permanent Population & 0.166 & 0.134 \\
\hline & Number of public transportation vehicles per 10000 persons & 0.081 & 0.153 \\
\hline & Per Capita Area of Paved Roads & 0.098 & 0.075 \\
\hline & Number of Hospital Beds per 1000 Persons & 0.079 & 0.153 \\
\hline & Average Number of Students Instructed by a Teacher & 0.173 & 0.128 \\
\hline & Annual Per Capita Disposable Income of Urban Households & 0.143 & 0.135 \\
\hline & Engel's Coefficient & 0.116 & 0.086 \\
\hline \multirow{6}{*}{ Environment system } & COD Discharge volume & 0.210 & 0.160 \\
\hline & $\mathrm{SO}_{2}$ Discharge volume & 0.189 & 0.209 \\
\hline & Emissions of industrial dust & 0.131 & 0.128 \\
\hline & Industrial solid waste generated & 0.144 & 0.191 \\
\hline & Per capita area of parks and green land & 0.200 & 0.156 \\
\hline & Greening coverage & 0.125 & 0.157 \\
\hline \multirow{5}{*}{ Economic system } & GDP & 0.208 & 0.211 \\
\hline & Per Capital GDP & 0.200 & 0.207 \\
\hline & Growth Rate of GDP & 0.160 & 0.151 \\
\hline & Third Industry of GDP & 0.211 & 0.218 \\
\hline & Volume of Retail Sales & 0.221 & 0.214 \\
\hline
\end{tabular}

\begin{tabular}{cccc} 
& \multicolumn{2}{c}{ TABLE-1 } & \\
\hline \multicolumn{1}{c}{ VALUE AND MEANING OF D } & Relationship of $\mathrm{f}(\mathrm{x}), \mathrm{f}(\mathrm{y}), \mathrm{f}(\mathrm{z})$ \\
\hline Rank & $\mathrm{D}$ & Meaning & \\
Coordinated development & $0.9-1.0$ & High level & \\
& $0.8-0.89$ & Fine level & \\
Interim development & $0.7-0.79$ & Middle level & $(1)$ when $\mathrm{m}=\mathrm{min}\{\mathrm{f}(\mathrm{x}), \mathrm{f}(\mathrm{y})$, \\
$\mathrm{f}(\mathrm{z})\}$, is delay system. \\
Disorder development & $0.6-0.69$ & Pass level & $(2)$ when $\mathrm{f}(\mathrm{x})=\mathrm{f}(\mathrm{y})=\mathrm{f}(\mathrm{z})$, three \\
& $0.5-0.59$ & Weaker level & system has been synchronization \\
development.
\end{tabular}


The standardized matrix $X=\left(x_{i j}^{*}\right)$ is calculated. i represents the evaluation objects, represent the evaluation index. $\mathrm{X}_{\max }$ and $\mathrm{X}_{\min }$ represent the maximum and the minimum value of the evaluation objects in the same evaluation index.

Method of weighting: In this research, the objective and subjective combined weighting method was employed to evaluate the index weight of each subsystem in the index system. That is to say, this research used the entropy method to determine the weight of each index. Entropy method, as a kind of objective weighting method, it determines the weights of indexes by analyzing the relevancy of different indexes and the information quantity provided by each index according to the original information coming from the objective environment. By using this weighting method, the deviation caused by subjective factors is avoided to some extent.

Suggest matrix $X=\left(x_{i j}\right)_{n \times m}$ represent one of evaluation system, of which $x_{i j}(1=1,2, \ldots, n ; j=1,2, \ldots m)$ represent the observed data of the $i$ evaluation objects and the $j$ indicators. For a given $\mathrm{j}$, the bigger difference of $\mathrm{x}_{\mathrm{ij}}$, the contribution of this index is bigger. This paper uses the entropy weight method to determine the weight of indicators in the subsystem steps:

Calculate the characteristics of $i$ object in the index $j$ :

$$
\mathrm{p}_{\mathrm{ij}}=\frac{\mathrm{x}_{\mathrm{ij}}}{\sum_{\mathrm{i}=1}^{\mathrm{n}} \mathrm{x}_{\mathrm{ij}}}
$$

Calculate the entropy of the index $\mathrm{j}$ :

$$
e_{j}=-k \sum_{i=1}^{n} p_{i j} \ln \left(p_{i j}\right)
$$

In the formula, $k=1 / \ln n, 0 \leq \mathrm{e}_{\mathrm{j}} \leq 1$. If $\mathrm{p}_{\mathrm{ij}}=0$, this runs counter to the complexity and uncertainty of the population, economy and environment system clearly.

Calculate the difference coefficient of index: $\mathrm{g}_{\mathrm{j}}=1-\mathrm{e}_{\mathrm{j}}$

Calculate the weight of the index:

$$
w_{j}=\frac{g_{j}}{\sum_{j=1}^{m} g_{j}}
$$

Analysis of the results: Based on the calculation method of the above evaluation model, this paper calculate the population agglomeration, economic and environmental evaluation index and its coupling coordination degree of Beijing and Shanghai from 2000 to 2012. The calculation results are given in Tables 3 and 4.

Analysis of the coupling and coordination degree: The coupling and coordination degree of population, environment and social economy of Beijing and Shanghai is in a rising trend, but coupling degrees is around 0.3 and the coordination degree is within 0.5 , which means the coupling relationship between the three systems is weak and the three systems can not form a strong coordinated development relations and lie in the Border level. Beijing is almost the same to Shanghai, but from the recent years, the coordination degree of Beijing is better than Shanghai, but the degrees of two cities have appeared the phenomenon of decline inordinately (Fig. 2).

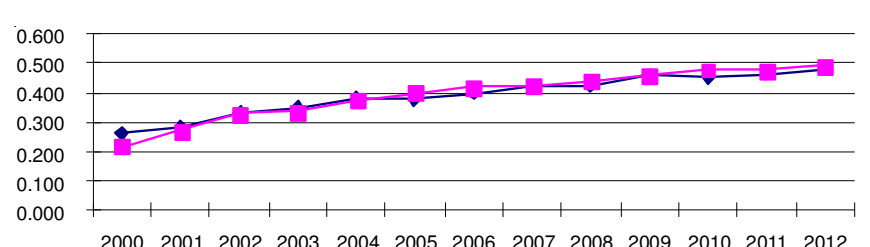

2000200120022003200420052006200720082009201020112012

\section{Shanghai - - Beijing}

Fig. 2. Coupling coordination degree of Beijing and Shanghai from 20002012

Development index analysis of each system: From the figure, we can see that the development process of each systems of two cities. In the two cities, Beijing and Shanghai, the three systems are in the slowly rising trend before 2007 and tend to synchronized development. The population development index is higher than the economic and environmental development, which shows that the growth of population and the improvement of population quality promote economic construction. But after 2007, the population development index significantly is weaker than the other two, which means the excessive

\begin{tabular}{|c|c|c|c|c|c|c|c|c|c|c|c|c|c|}
\hline & & $\begin{array}{r}\text { PO } \\
\text { AND } 1\end{array}$ & $\begin{array}{l}\text { LATIO } \\
\text { COUP }\end{array}$ & $\begin{array}{l}\mathrm{ECON} \\
\mathrm{NG} \mathrm{CO}\end{array}$ & $\begin{array}{l}\text { MIC AN } \\
\text { RDINA }\end{array}$ & $\begin{array}{l}\text { TABLE } \\
\text { ENVIR } \\
\text { ON DEC }\end{array}$ & $\begin{array}{l}\text { NMENT } \\
\text { EE OF }\end{array}$ & $\begin{array}{l}\text { L EVAI } \\
\text { IANGH }\end{array}$ & $\begin{array}{c}\text { ATION } \\
\text { FROM }\end{array}$ & $\begin{array}{l}\text { NDEX } \\
00-201\end{array}$ & & & \\
\hline Year & 2000 & 2001 & 2002 & 2003 & 2004 & 2005 & 2006 & 2007 & 2008 & 2009 & 2010 & 2011 & 2012 \\
\hline Population & 0.375 & 0.468 & 0.540 & 0.531 & 0.662 & 0.671 & 0.667 & 0.551 & 0.546 & 0.640 & 0.477 & 0.465 & 0.478 \\
\hline Economic & 0.100 & 0.114 & 0.165 & 0.175 & 0.262 & 0.274 & 0.363 & 0.540 & 0.529 & 0.621 & 0.705 & 0.762 & 0.849 \\
\hline Environmental & 0.242 & 0.259 & 0.410 & 0.530 & 0.469 & 0.442 & 0.449 & 0.478 & 0.536 & 0.652 & 0.672 & 0.748 & 0.820 \\
\hline $\mathrm{C}$ & 0.291 & 0.285 & 0.297 & 0.297 & 0.311 & 0.312 & 0.323 & 0.333 & 0.333 & 0.333 & 0.329 & 0.325 & 0.323 \\
\hline
\end{tabular}
expansion of population has brought certain hysteresis on economic development and environment.

\begin{tabular}{ccccccccccccccc}
\hline & \multicolumn{10}{c}{ TABLE-4 } \\
& \multicolumn{10}{c}{ POPULATION, ECONOMIC AND ENVIRONMENTAL EVALUATION INDEX } \\
& \multicolumn{10}{c}{ AND ITS COUPLING COORDINATION DEGREE OF BEIJING FROM 2000-2012 } \\
\hline Year & 2000 & 2001 & 2002 & 2003 & 2004 & 2005 & 2006 & 2007 & 2008 & 2009 & 2010 & 2011 & 2012 \\
\hline Population & 0.210 & 0.318 & 0.515 & 0.435 & 0.558 & 0.619 & 0.672 & 0.440 & 0.496 & 0.540 & 0.560 & 0.573 & 0.608 \\
Economic & 0.097 & 0.125 & 0.156 & 0.188 & 0.317 & 0.323 & 0.411 & 0.542 & 0.497 & 0.584 & 0.695 & 0.755 & 0.840 \\
Environment & 0.134 & 0.270 & 0.428 & 0.471 & 0.424 & 0.523 & 0.524 & 0.633 & 0.787 & 0.802 & 0.830 & 0.731 & 0.775 \\
C & 0.317 & 0.309 & 0.296 & 0.309 & 0.325 & 0.322 & 0.327 & 0.330 & 0.325 & 0.328 & 0.329 & 0.331 & 0.330 \\
D & 0.216 & 0.271 & 0.329 & 0.336 & 0.375 & 0.396 & 0.418 & 0.421 & 0.439 & 0.459 & 0.478 & 0.477 & 0.495 \\
\hline
\end{tabular}


The development of economic and environmental system of the two cities is synchronous. Along with the development of the economy, the evolution of environment will be better. But in recent years, environmental index are weaker than the trend of economic development, especially in Beijing, the environmental index started to decline (Figs. 3 and 4).

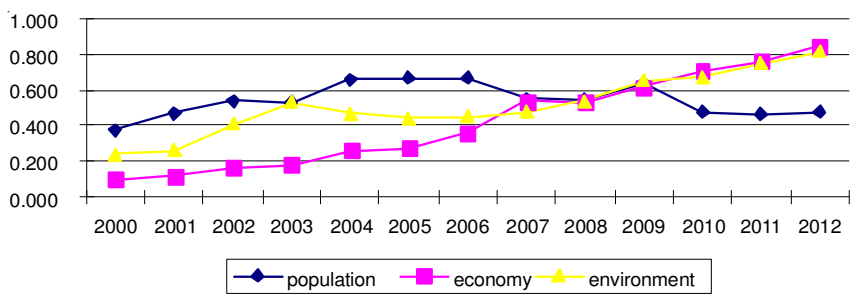

Fig. 3. Development index of Shanghai from 2000-2012

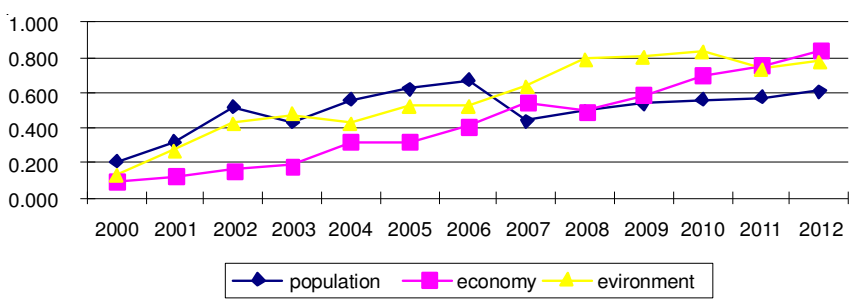

Fig. 4. Development index of Beijing from 2000-2012

Key factors analysis influencing the coordination degree: The various index weights of subsystems show that various index have different impact to the system coupling coordination. These indicators that affect the population, environment and social economy system coordination of Beijing are: Permanent population density, Average number of students instructed by a teacher, Third Industry of GDP, Total Volume of Retail Sales, Per Capita Area of Parks and Green Land, COD Discharge Volume. These indicators that affect the population, environment and social economy system coordination of Shanghai are: Number of Public Transportation Vehicles Per 10000 Persons, Number of Hospital Beds per 1000 Persons, The Third Industry of GDP, Total Volume of Retail Sales, $\mathrm{SO}_{2}$ Discharge Volume, Industrial Solid Waste Generated. So in order to promote the coordinated development of the three systems of Beijing and Shanghai, we must start from these measures to gradually improve.

Conclusions and policy recommendations: In Chinese metropolises like Beijing and Shanghai, the population influx brings economic prosperity as well as urban congestion, rising cost of living, such as serious environmental pollution phenomenon, this paper construct the comprehensive evaluation system based on the concept of coupling and coordination degree, which includes population, environment and social economic environment. Through the analysis of the two big cities, some of the conclusions were obtained. The coupling relationship of mutual influence and mutual restriction exist between population agglomeration, social economy and environment. If the three systems can't coordinate development, sustainable development will not necessarily. Beijing and Shanghai have weak coupling coordination relations between the three systems, although have the rising, but almost are all in on the verge of disorder. Beijing and Shanghai need a lot of improvement and improve. In the calculation and analysis, we found that the important factors that affect the different urban coordinated development are different; therefore in the process of improvement and improved coordination degree of the city, we suggest that should start from the relative key factors and disharmonious factors.

\section{ACKNOWLEDGEMENTS}

This research was supported by the soft science project of Henan province Science and Technology Agency (132400410541) and Natural Science Research projects of Henan Province Education Department (12B630053).The author is grateful to the anonymous referee for a careful checking of the details and for helpful comments that improved this paper.

\section{REFERENCES}

1. T. Ramilan, F. Scrimgeour and D. Marsh, Math. Comput. Simul., 81, 1344 (2011).

2. J. He and H. Wang, Ecol. Econ., 76, 49 (2012).

3. B. Liddle, Environ. Model. Softw., 40, 255 (2013).

4. S. Guohui and L. Yunfeng, Procedia Environ. Sci., 12, 785 (2012).

5. G. Liu, Z. Yang, B. Chen and S. Ulgiati, Ecol. Modell., 271, 90 (2014).

6. K. Men, P. Zhang, K. Zhao and S. Zhu, Statistical and Application, 2, 9 (2013).

7. H.L. Jiang and J.M. He, Soft. Sci., 3, 63 (2010).

8. Y.M. Wu and Y. Zhang, Resources Sci., 1, 25 (2008).

9. L. Xie, G. Zhu and Q. Chen, Syst. Eng., 8, 113 (2012).

10. X.J. Qi and Y.F. Tong, China Population Resour. Environ., 2, 110 (2008).

11. Z.X. Wu, D. Yu and S.-P. Wang, Math. Pract. Theory, 6, 33 (2011).

12. Z.G. Guo, Population Economics, 6, 12 (2000). 